\title{
Laparoscopy-assisted proximal gastrectomy for early gastric cancer is an ugly duckling with unsolved concerns: oncological safety, late complications, and functional benefit
}

\author{
Sang-Hoon Ahn $\cdot$ Ju Hee Lee $\cdot$ Do Joong Park • \\ Hyung-Ho Kim
}

Received: 6 January 2013/Accepted: 5 February 2013/Published online: 13 March 2013

(c) The International Gastric Cancer Association and The Japanese Gastric Cancer Association 2013

There are notable changes in that the proportion of early gastric cancer (EGC) and proximal gastric cancer has increased continuously during the past 20 years, from $24.8 \%$ to nearly $50 \%$ and from 5.3 to $14.0 \%$, respectively. Proximal EGC consists of $30.3 \%$ of all proximal gastric cancer whereas distal EGC consists of $51.5 \%$ of all distal gastric cancer [1-3]. Accordingly, more and more surgeons are interested in laparoscopic gastrectomy for early gastric cancer. In proximal EGC and the concept of minimally invasive surgery, laparoscopy-assisted proximal gastrectomy (LAPG) is a theoretically better treatment option than others [i.e., open proximal gastrectomy, open total gastrectomy, and laparoscopy-assisted total gastrectomy (LATG)]. However, LAPG is not popular these days. Even including the open cases, proximal gastrectomy was performed in only $141(1.0 \%)$ patients in 2009 [2]. Proximal gastrectomy (PG) is not yet the standard treatment for patients with proximal early gastric cancer (EGC): it is still classified as an investigational treatment by the Japanese gastric cancer treatment guidelines [4]. The application of proximal gastrectomy to proximal EGC has been limited by the following three main concerns. The first is oncological concern, mainly focused on limited lymph node dissection; the second is late complications such as reflux esophagitis and anastomotic stricture, related to reconstruction methods; and the third is functional benefits.

S.-H. Ahn · J. H. Lee · D. J. Park $(\bowtie) \cdot$ H.-H. Kim

Department of Surgery, Seoul National University

College of Medicine, Seoul, Korea

e-mail: djpark@snubh.org

S.-H. Ahn · J. H. Lee $\cdot$ D. J. Park · H.-H. Kim

Department of Surgery, Seoul National University Bundang

Hospital, 300 Gumi-dong, Bundang-gu, Seongnam-si,

Gyenggi-do 463-707, Korea
In a recent systematic and meta-analysis comparing total gastrectomy with proximal gastrectomy, it was concluded that total gastrectomy and proximal gastrectomy had similar overall survival outcomes for proximal gastric cancer. However, proximal gastrectomy with esophagogastrostomy exhibited a higher incidence of reflux esophagitis and anastomotic stenosis. Total gastrectomy was therefore recommended for proximal gastric cancer [5].

However, the number of cases of proximal EGC has been increasing in Korea because of national screening programs and advances in endoscopic diagnosis and devices [1-3]. Is it feasible for all these patients with EGC, who are capable of showing a good survival rate after surgery, to undergo open total gastrectomy?

As a minimally invasive surgery, laparoscopic gastrectomy has several advantages over open gastrectomy, especially with respect to early postoperative outcomesthat is, it reduces postoperative pain, surgical stress, and estimated blood loss, it accelerates recovery and return to normal bowel function and oral intake, and it reduces the duration of hospital stay [6-9]. Because gastric cancer is mostly located in the distal area in patients in Eastern countries, laparoscopic distal gastrectomy has been a more common procedure than laparoscopic total or proximal gastrectomy. However, recently, some positive outcomes of laparoscopic total or proximal gastrectomy have been reported [10-12]. In this context, laparoscopic proximal gastrectomy is an attractive treatment option for proximal EGC when considering the prognosis of EGC, the advantages of a minimally invasive surgery and function preservation, including improved nutrition, prevention of anemia, improved production of gut hormones, and a reduction of postoperative complaints [13-16].

If the incidence of late complications such as reflux esophagitis and anastomotic stenosis could be decreased to 
that of total gastrectomy, laparoscopy-assisted proximal gastrectomy (LAPG) has the potential to become the standard procedure for proximal gastrectomy. The most important technical challenge of LAPG may be the reconstruction method, which needs to be designed to prevent reflux symptoms and anastomotic strictures. Several reconstruction methods have already been reported; however, an optimal reconstruction after LAPG has not yet been established.

Several previous studies have applied direct esophagogastric anastomosis as the reconstruction method, probably because it is simple and needs only one anastomosis. Antireflux procedures such as a gastric tube formation, fundoplication, esophagopexy with crural repair, and pyloroplasty have been used for preventing reflux esophagitis and anastomotic strictures. However, all these methods involved esophagogastrostomy, and the results were disappointing because the rates of reflux esophagitis and anastomotic stenosis were still high $[10,17,18]$. A good alternative to esophagogastrostomy reconstruction after proximal gastrectomy is the Roux-en-Y type esophagojejunostomy (EJstomy), which is the most powerful anti-reflux reconstruction. There are two kinds of E-Jstomy that can be performed after proximal gastrectomy: jejunal interposition and double-tract reconstruction (DTR). Jejunal interposition has been introduced as an alternative method for preventing severe reflux and is widely performed in open surgery; however, laparoscopic jejunal interposition has not yet gained acceptance because of its technical complexities. These complexities include the formation of a pedicled jejunal flap and the formation of three anastomoses: the mean surgical time was also relatively long (233-614 min) [19, 20]. Double-tract reconstruction consists of three anastomoses: Roux-en Y esophagojejunostomy, gastrojejunostomy $15 \mathrm{~cm}$ below esophagojejunostomy, and jejunojejunostomy $20 \mathrm{~cm}$ below gastrojejunostomy.

Schwartz et al. raised questions about our comparative study in the editorial in this issue. First, our report is the first comparative study on LAPG versus LATG. Of course, this is not too surprising anymore in the setting of proper expertise. However, LAPG and LATG are still technically demanding procedures, in contrast to laparoscopy-assisted distal gastrectomy (LADG), so we cannot directly compare our results with those of LADG as they said. We think surgeries that involve the esophagus are still difficult operations even in the open setting. For example, recently, our Korean Laparoscopic Gastrointestinal Surgery Study (KLASS) group is going to start a prospective registration observatory study between open total gastrectomy and LATG (KLASS-03 study), which shows directly the difficulty of esophagojejunostomy in laparoscopy.

Second, the choice of surgical approach, LAPG or LATG, was determined by the tumor factor. If the tumor size was relatively large and the volume of remnant stomach was too small to perform esophagogastrostomy, we performed LATG. However, if we use another reconstruction method other than direct esophagogastrectomy, the indication will be expanded to nearly all early proximal gastric cancer.

Third, the overall survival rate was similar in the two groups of our study. Only two cases in the LAPG group and three cases in the LATG group expired. All these expired cases were not related to gastric cancer, which means the disease-specific survival rate was $100 \%$. For this reason, we did not include disease-specific survival in our study. Furthermore, in the Japanese gastric guidelines (3rd edition), proximal gastrectomy is classified as a modified surgery, which can be done in the EGC except the indication of endoscopic submucosal dissection. These guidelines recommend that D1 or D1 + lymph node dissection (LND) should be performed in proximal gastrectomy, which is based on the knowledge of which lymph node stations are most likely to be involved among proximal EGC. The lymph node stations of most concern in proximal gastrectomy are nos. 5, 6, and 10. According to several retrospective reports, there is no lymph node metastasis along the lower stomach and splenic hilum in gastric cancers that were confined to the muscularis propria [21-25]. Based on these data, LND in LAPG for proximal EGC D1 or D1 + LND is thought to be enough [26].

Fourth, at our institution, LAPG with esophagogastrostomy was performed since May 2003 as in this study; however, the rate of reflux symptoms and anastomotic stenosis after esophagogastrostomy was still high, even though we gradually began to perform a few anti-reflux procedures as well (i.e., gastric tube formation, esophagopexy with crural repair, and fundoplication) [10]. Therefore, in April 2009, LAPG with DTR was introduced at our institute. We think DTR is an easier and simpler procedure than jejunal interposition under laparoscopy. These encouraging data led us to plan a phase III prospective RCT about LAPG versus LATG. As to functional outcomes, our study has several weak points because of its retrospective nature, such as the lack of data of the quality of life using validated questionnaires.

Finally, we, in an Eastern country, do not have much experience and definite data in adjuvant and neoadjuvant chemotherapy after LAPG and LATG because laparoscopic procedures are usually applied to the early stage of gastric cancer, which usually does not require chemotherapy. However, the laparoscopic approach, leading to lower postoperative morbidity than the open method, might be a good option for gastric cancer patients who have received perioperative chemotherapy or chemoradiation treatment in Western centers.

In conclusion, LAPG will be a good alternative procedure for proximal gastric cancer if the rate of reflux 
esophagitis and anastomotic stenosis can be low as LATG. We are planning phase III multicenter prospective randomized clinical trials between LAPG and LATG, which should answer a goodly portion of unsolved questions about proximal gastrectomy.

\section{References}

1. Ahn HS, Lee HJ, Yoo MW, Jeong SH, Park DJ, Kim HH, Kim WH, Lee KU, Yang HK. Changes in clinicopathological features and survival after gastrectomy for gastric cancer over a 20 -year period. Br J Surg. 2011;98(2):255-60.

2. Jeong O, Park Y-K. Clinicopathological features and surgical treatment of gastric cancer in South Korea: the results of 2009 nationwide survey on surgically treated gastric cancer patients. J Gastric Cancer. 2011;11(2):69-77.

3. Kim HH, KLASS (Korean Laparoscopic Gastrointestinal Surgery Study Group). 2004 Nationwide Gastric Cancer Survey in Korea. J Gastric Cancer 2005;5(4):285-303.

4. Japanese Gastric Cancer Association. Japanese gastric cancer treatment guidelines 2010 (ver. 3). Gastric Cancer 2011;14(2): 113-23.

5. Wen L, Chen XZ, Wu B, Chen XL, Wang L, Yang K, Zhang B, Chen ZX, Chen JP, Zhou ZG, et al. Total vs. proximal gastrectomy for proximal gastric cancer: a systematic review and metaanalysis. Hepatogastroenterology. 2012;59(114):633-40.

6. Kim HH, Hyung WJ, Cho GS, Kim MC, Han SU, Kim W, Ryu SW, Lee HJ, Song KY. Morbidity and mortality of laparoscopic gastrectomy versus open gastrectomy for gastric cancer: an interim report-a phase III multicenter, prospective, randomized trial (KLASS trial). Ann Surg. 2010;251(3):417-20.

7. Hwang SH, do Park J, Jee YS, Kim MC, Kim HH, Lee HJ, Yang HK, Lee KU. Actual 3-year survival after laparoscopy-assisted gastrectomy for gastric cancer. Arch Surg. 2009;144(6):559-64. discussion 565.

8. Kim W, Song KY, Lee HJ, Han SU, Hyung WJ, Cho GS. The impact of comorbidity on surgical outcomes in laparoscopyassisted distal gastrectomy: a retrospective analysis of multicenter results. Ann Surg. 2008;248(5):793-9.

9. Kim MC, Jung GJ, Kim HH. Morbidity and mortality of laparoscopy-assisted gastrectomy with extraperigastric lymph node dissection for gastric cancer. Dig Dis Sci. 2007;52(2):543-8.

10. Ahn SH, Lee JH, Park DJ, Kim HH. Comparative study of clinical outcomes between laparoscopy-assisted proximal gastrectomy (LAPG) and laparoscopy-assisted total gastrectomy (LATG) for proximal gastric cancer. Gastric Cancer. 2012 [Epub ahead of print]

11. Eom BW, Kim YW, Lee SE, Ryu KW, Lee JH, Yoon HM, Cho SJ, Kook MC, Kim SJ. Survival and surgical outcomes after laparoscopy-assisted total gastrectomy for gastric cancer: casecontrol study. Surg Endosc. 2012;26(11):3273-81
12. Lee JH, Ahn SH, Park DJ, Kim HH, Lee HJ, Yang HK. Laparoscopic total gastrectomy with D2 lymphadenectomy for advanced gastric cancer. World J Surg. 2012;36(10):2394-9

13. Adachi Y, Inoue T, Hagino Y, Shiraishi N, Shimoda K, Kitano S. Surgical results of proximal gastrectomy for early-stage gastric cancer: jejunal interposition and gastric tube reconstruction. Gastric Cancer. 1999;2(1):40-5.

14. Takeshita K, Saito N, Saeki I, Honda T, Tani M, Kando F, Endo M. Proximal gastrectomy and jejunal pouch interposition for the treatment of early cancer in the upper third of the stomach: surgical techniques and evaluation of postoperative function. Surgery (St. Louis). 1997;121(3):278-86.

15. Furukawa $H$, Hiratsuka $M$, Imaoka $S$, Ishikawa $O$, Kabuto $T$, Sasaki Y, Kameyama M, Ohigashi H, Nakano H, Yasuda T. Limited surgery for early gastric cancer in cardia. Ann Surg Oncol. 1998;5(4):338-41.

16. Kameyama J, Ishida H, Yasaku Y, Suzuki A, Kuzu H, Tsukamoto M. Proximal gastrectomy reconstructed by interposition of a jejunal pouch. Surgical technique. Eur J Surg. 1993;159(9):491-3.

17. An JY, Youn HG, Choi MG, Noh JH, Sohn TS, Kim S. The difficult choice between total and proximal gastrectomy in proximal early gastric cancer. Am J Surg. 2008;196(4):587-91.

18. Yoo CH, Sohn BH, Han WK, Pae WK. Long-term results of proximal and total gastrectomy for adenocarcinoma of the upper third of the stomach. Cancer Res Treat. 2004;36(1):50-5.

19. Uyama I, Sugioka A, Fujita J, Komori Y, Matsui H, Hasumi A. Completely laparoscopic proximal gastrectomy with jejunal interposition and lymphadenectomy. J Am Coll Surg. 2000; 191(1):114-9.

20. Kinoshita T, Gotohda N, Kato Y, Takahashi S, Konishi M. Laparoscopic proximal gastrectomy with jejunal interposition for gastric cancer in the proximal third of the stomach: a retrospective comparison with open surgery. Surg Endosc. 2013;27(1):146-53

21. Kitamura K, Yamaguchi T, Nishida S, Yamamoto K, Ichikawa D, Okamoto K, Taniguchi H, Hagiwara A, Sawai K, Takahashi T. The operative indications for proximal gastrectomy in patients with gastric cancer in the upper third of the stomach. Surg Today. 1997;27(11):993-8.

22. Kaminishi M, Takubo K, Mafune K. The diversity of gastric cancer: pathogenesis, diagnosis and therapy. Berlin: Springer; 2005. p 263

23. Kwon SJ. Prognostic impact of splenectomy on gastric cancer: results of the Korean Gastric Cancer Study Group. World J Surg. 1997;21(8):837-44.

24. Monig SP, Collet PH, Baldus SE, Schmackpfeffer K, Schroder W, Thiele J, Dienes HP, Holscher AH. Splenectomy in proximal gastric cancer: frequency of lymph node metastasis to the splenic hilus. J Surg Oncol. 2001;76(2):89-92.

25. Shin SH, Jung H, Choi SH, An JY, Choi MG, Noh JH, Sohn TS, Bae JM, Kim S. Clinical significance of splenic hilar lymph node metastasis in proximal gastric cancer. Ann Surg Oncol. 2009; 16(5):1304-9.

26. Sano T, Aiko T. New Japanese classifications and treatment guidelines for gastric cancer: revision concepts and major revised points. Gastric Cancer. 2011;14(2):97-100. 